\title{
Simulation of bedrock motion to obtain PGA values
}

\author{
Prof. Ranjith Dissanayake \\ Head, Department of Civil Engineering, \\ University of Peradeniya
}




\section{Objective}

- To develop the seismic hazard map for Sri Lanka using numerical simulation. 


\section{Seismicity of Earth}

Preliminary Determination of Epicenters 358,214 Events, 1963 - 1998

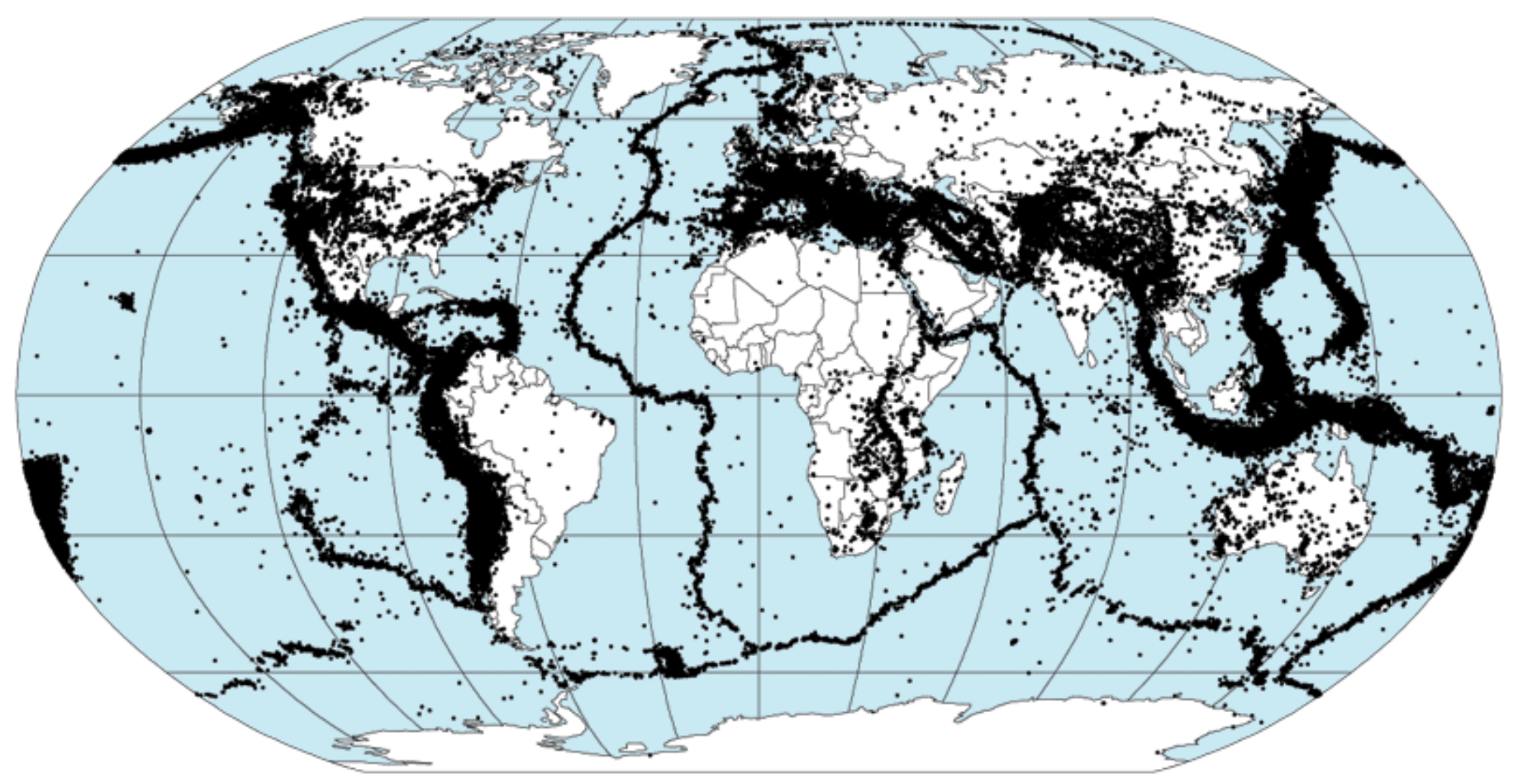




\section{I ndo-Australian Plate}

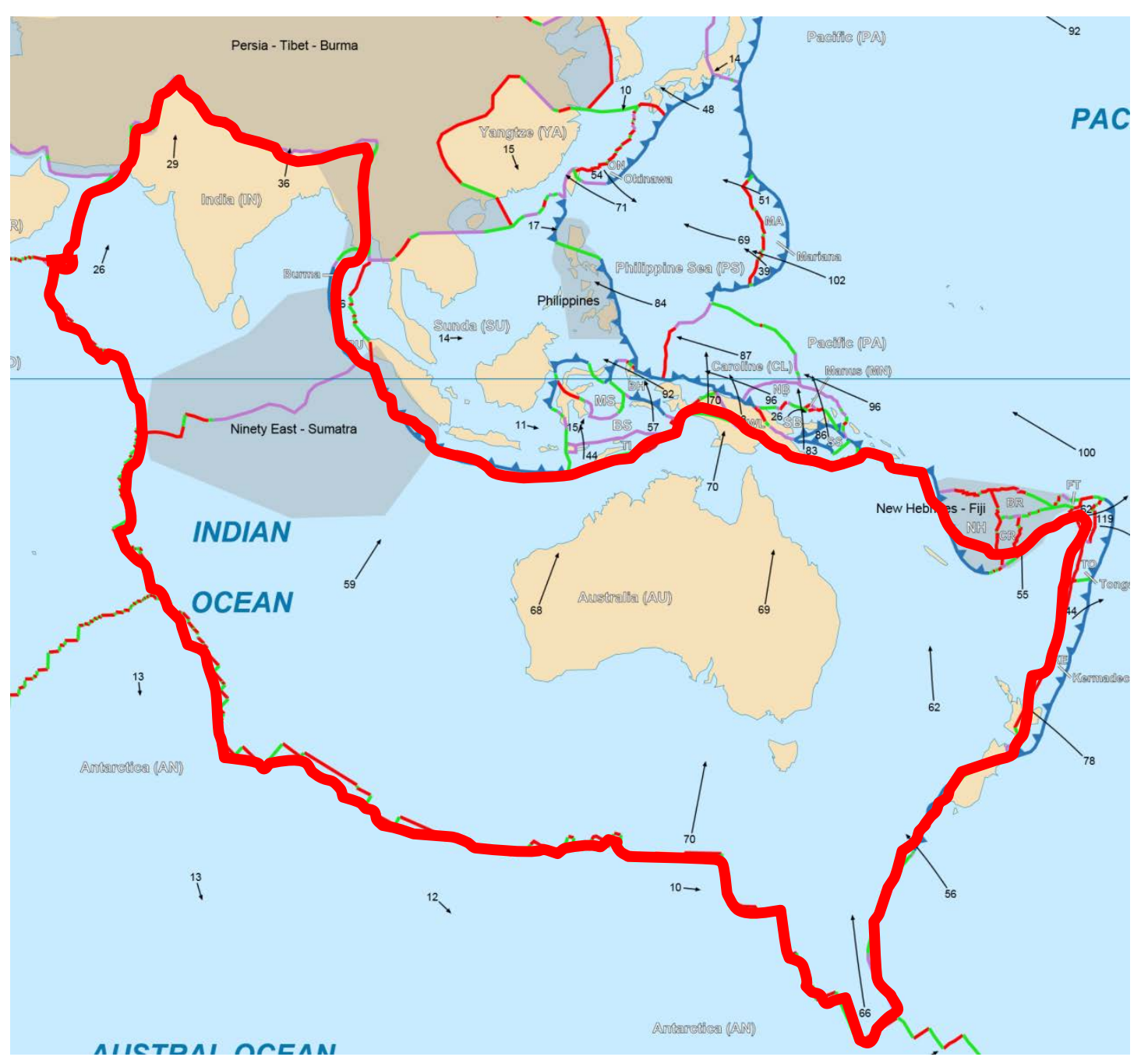




\section{I ntraplate Earthquake: Bhuj Earthquake (2001, Mw=7.6)}
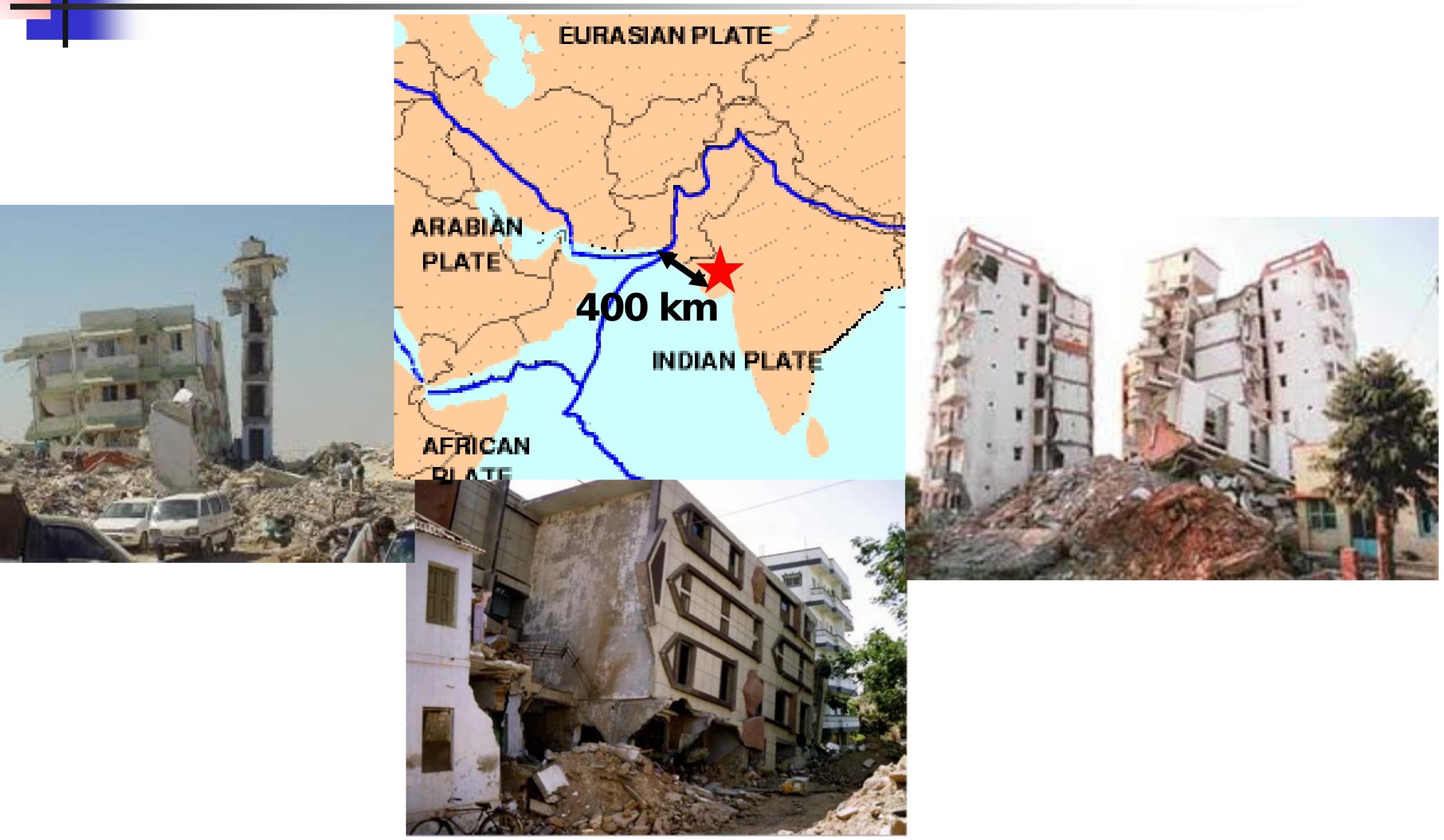


\section{Earthquake in Vicinity of Sri Lanka (1000 - 2012 A.D.)}

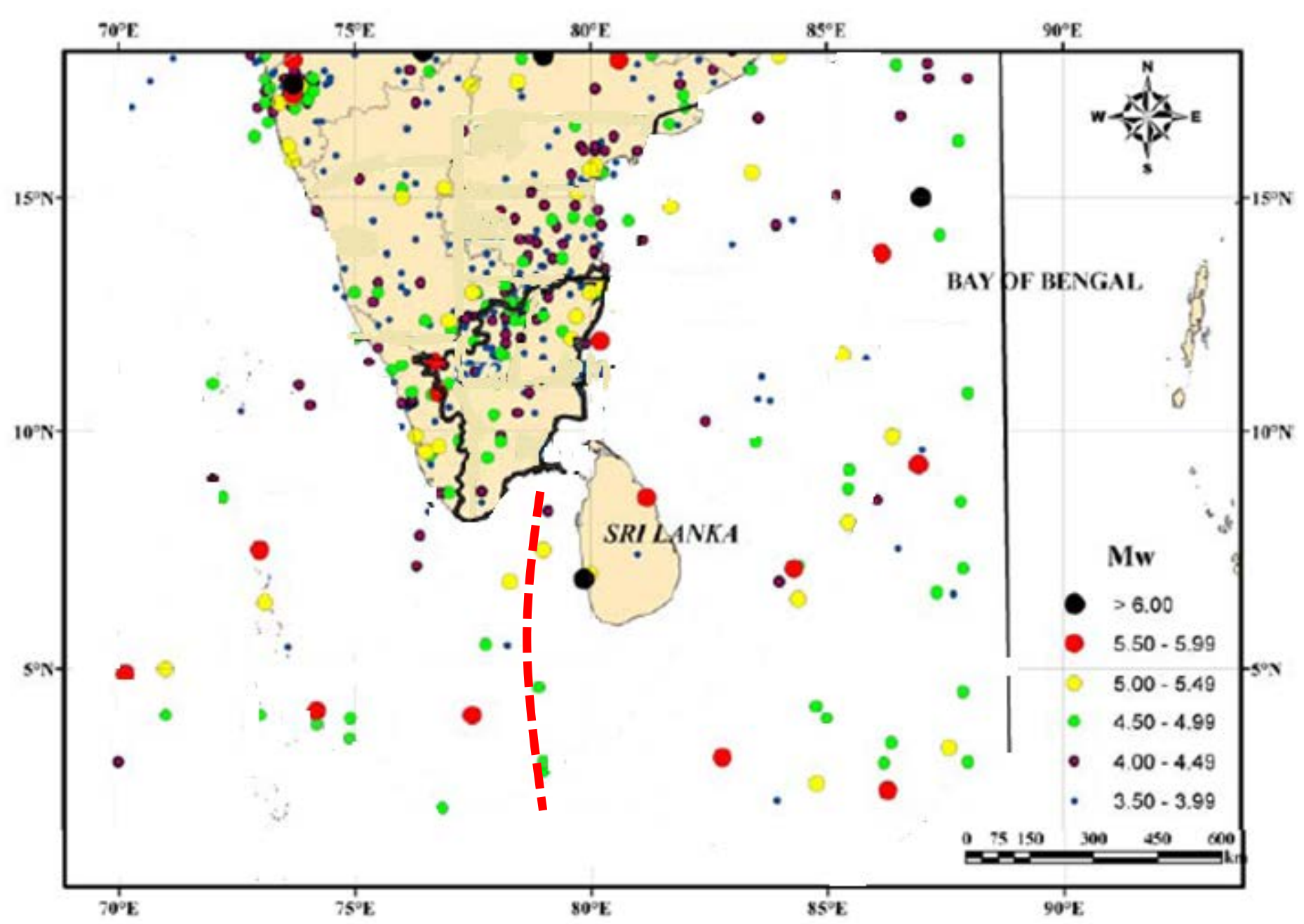




\section{Sources of Data Collection}

- Chandra [1977],

- Rao and Rao [1984],

- Guha and Basu [1993],

- Iyengar et al. [1999] and

- Vithanage et al

- Jaiswal and Sinha [2007]

- National Earthquake Information Centre (NEIC)

- International Seismological Centre (ISC),

- Incorporated Research Institutions for Seismology (IRIS),

- India Metrological Department (IMD)

- USGS Database

- PEER Database 


\section{FLAC}

- FLAC is a two-dimensional finite difference program for engineering mechanics computation.

- FLAC's analysis capability to a wide range of dynamic problems in disciplines such as earthquake engineering, seismology

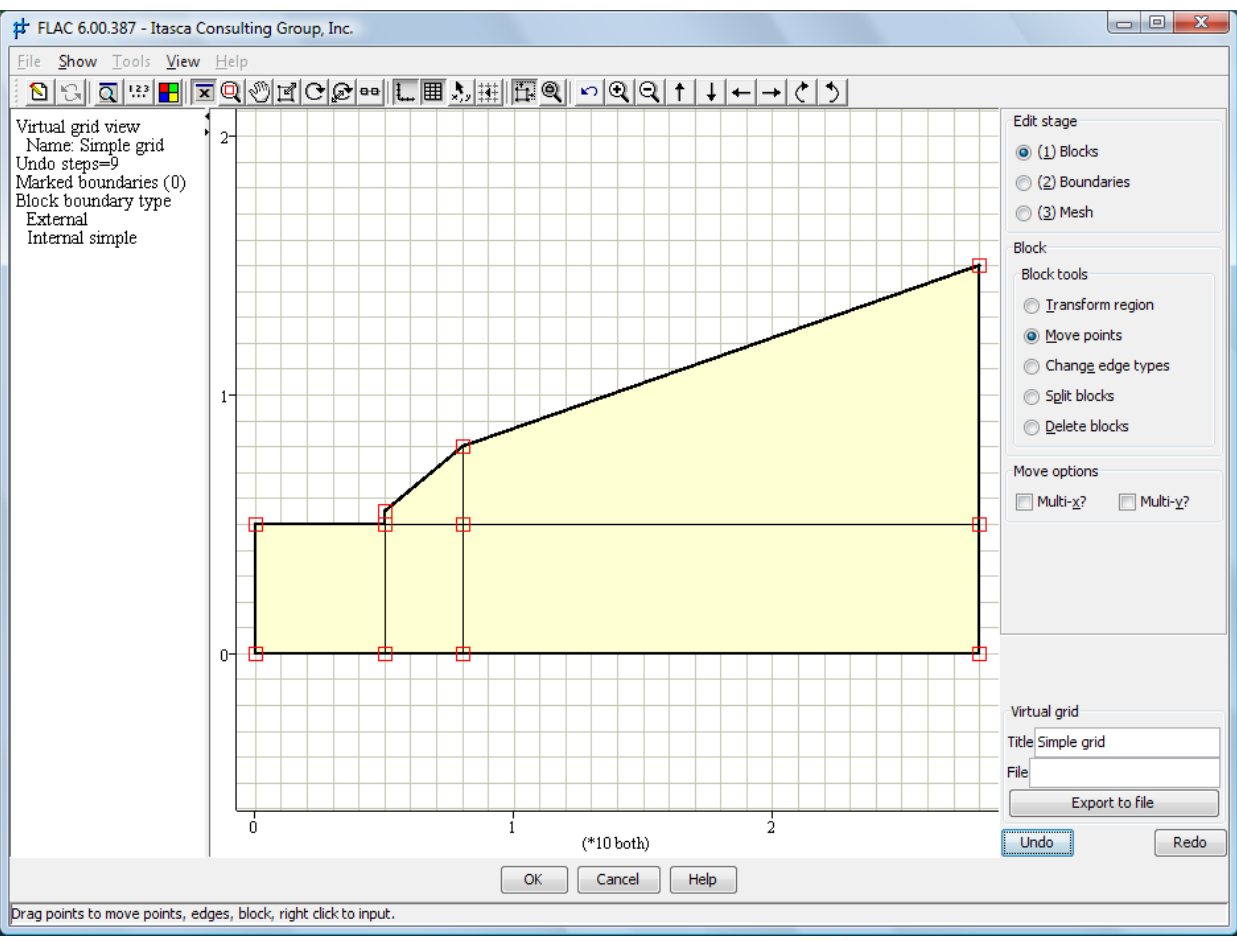
and mine rock bursts.

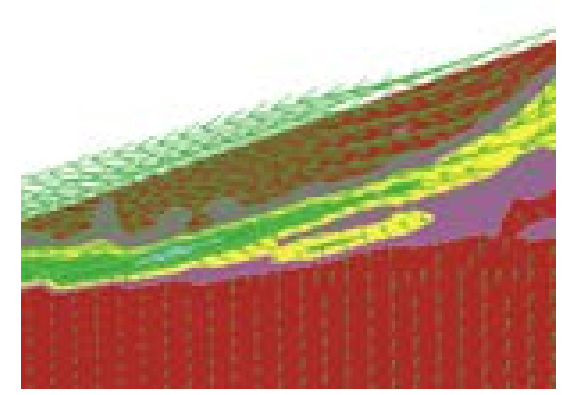




\section{Finite Difference Method - Overview}

- Replace derivatives of governing equations with algebraic difference quotients

- Results in a system of algebraic equations solvable for dependent variables at discrete grid points

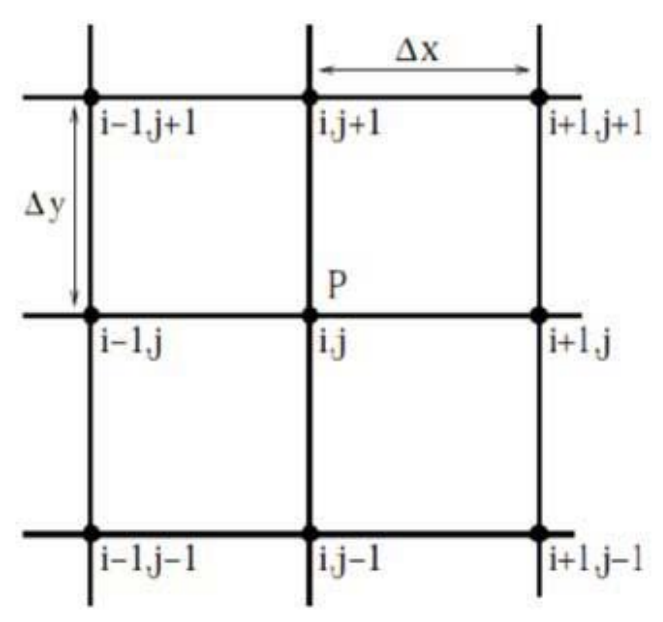

- Analytical solutions provide closed-form expressions - variation of dependent variables in the domain

- Numerical solutions (finite difference) values at discrete points in the domain 


\section{Grid Discretization}

- For accurate representation of wave transmission through a model, element size $\Delta \mathrm{l}$, must be smaller than approximately one-tenth to one-eight of the wave length of the input wave.

$$
\Delta l \leq \frac{\lambda}{10}
$$

- $\lambda$ is the wave length associated with the highest frequency component that contains appreciable energy. 


\section{D-Wave Equation}

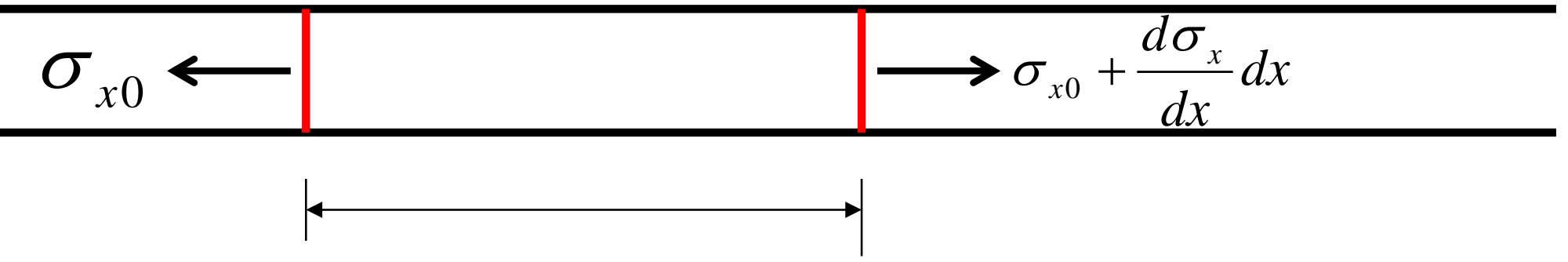

Considering the dynamic equilibrium

$$
\begin{gathered}
\left(\sigma_{x 0}+\frac{d \sigma_{x}}{d x} d x\right) A-\sigma_{x 0}=\rho A d x \frac{d^{2} u}{d t^{2}} \\
\frac{\partial^{2} u}{\partial t^{2}}=v_{P}^{2} \frac{\partial^{2} u}{\partial x^{2}}
\end{gathered}
$$




\section{Wave Equation}

- Considering second order wave equation.

$$
\frac{\partial^{2} u}{\partial t^{2}}=v^{2} \frac{\partial^{2} u}{\partial x^{2}}
$$

- Discretization is implemented by replacing the second order derivatives in the wave equation by their standard finite difference approximations :

$$
\begin{aligned}
& \frac{\partial^{2} u}{\partial t^{2}}\left(t_{j}, x_{m}\right) \approx \frac{u\left(t_{j+1}, x_{m}\right)-2 u\left(t_{j}, x_{m}\right)+u\left(t_{j-1}, x_{m}\right)}{(\Delta t)^{2}}+\mathrm{O}\left((\Delta t)^{2}\right) \\
& \frac{\partial^{2} u}{\partial x^{2}}\left(t_{j}, x_{m}\right) \approx \frac{u\left(t_{j}, x_{m+1}\right)-2 u\left(t_{j}, x_{m}\right)+u\left(t_{j}, x_{m-1}\right)}{(\Delta x)^{2}}+\mathrm{O}\left((\Delta x)^{2}\right)
\end{aligned}
$$




\section{Selected Cross Sections}

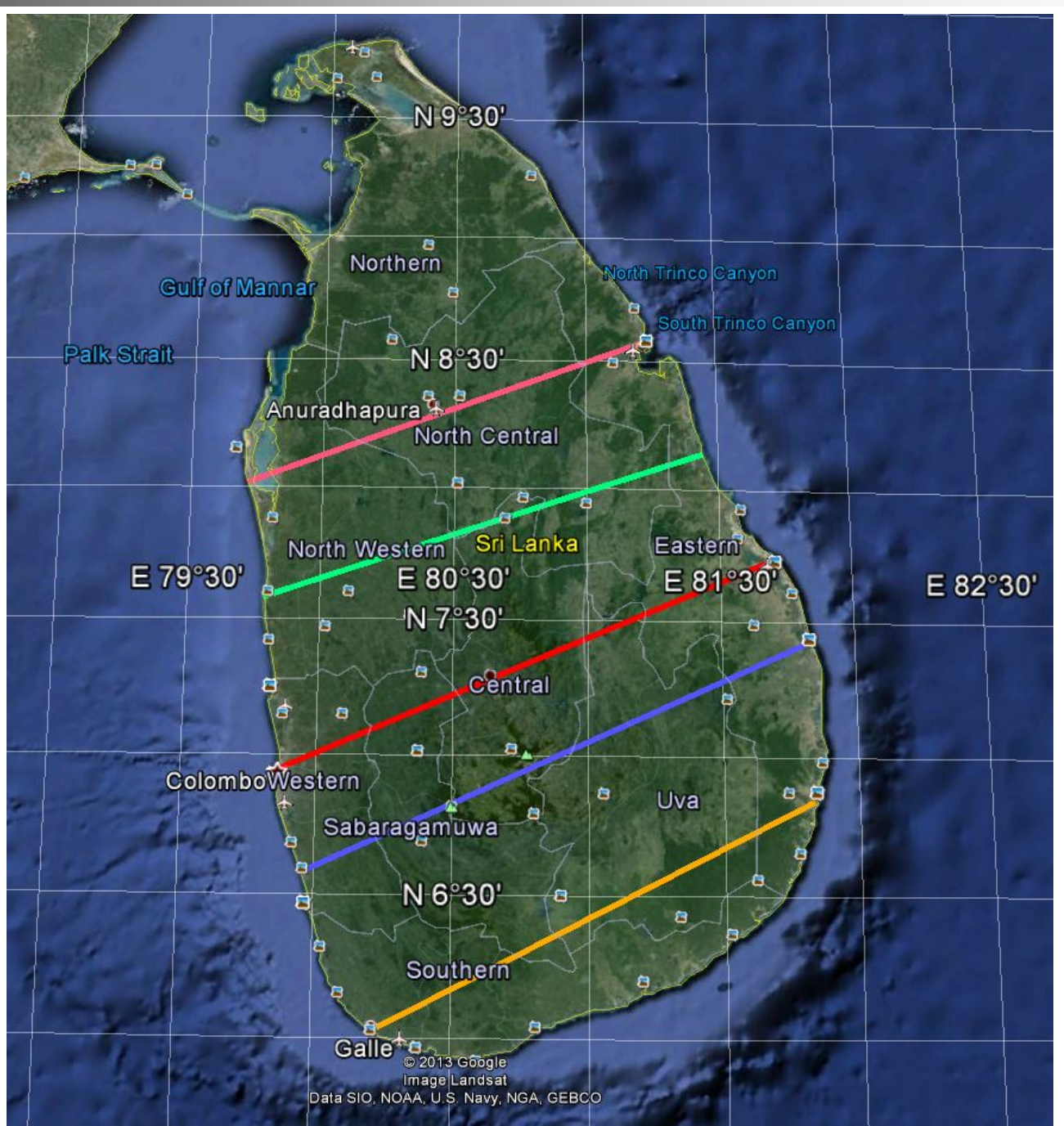




\section{Cross section obtained from Google earth}

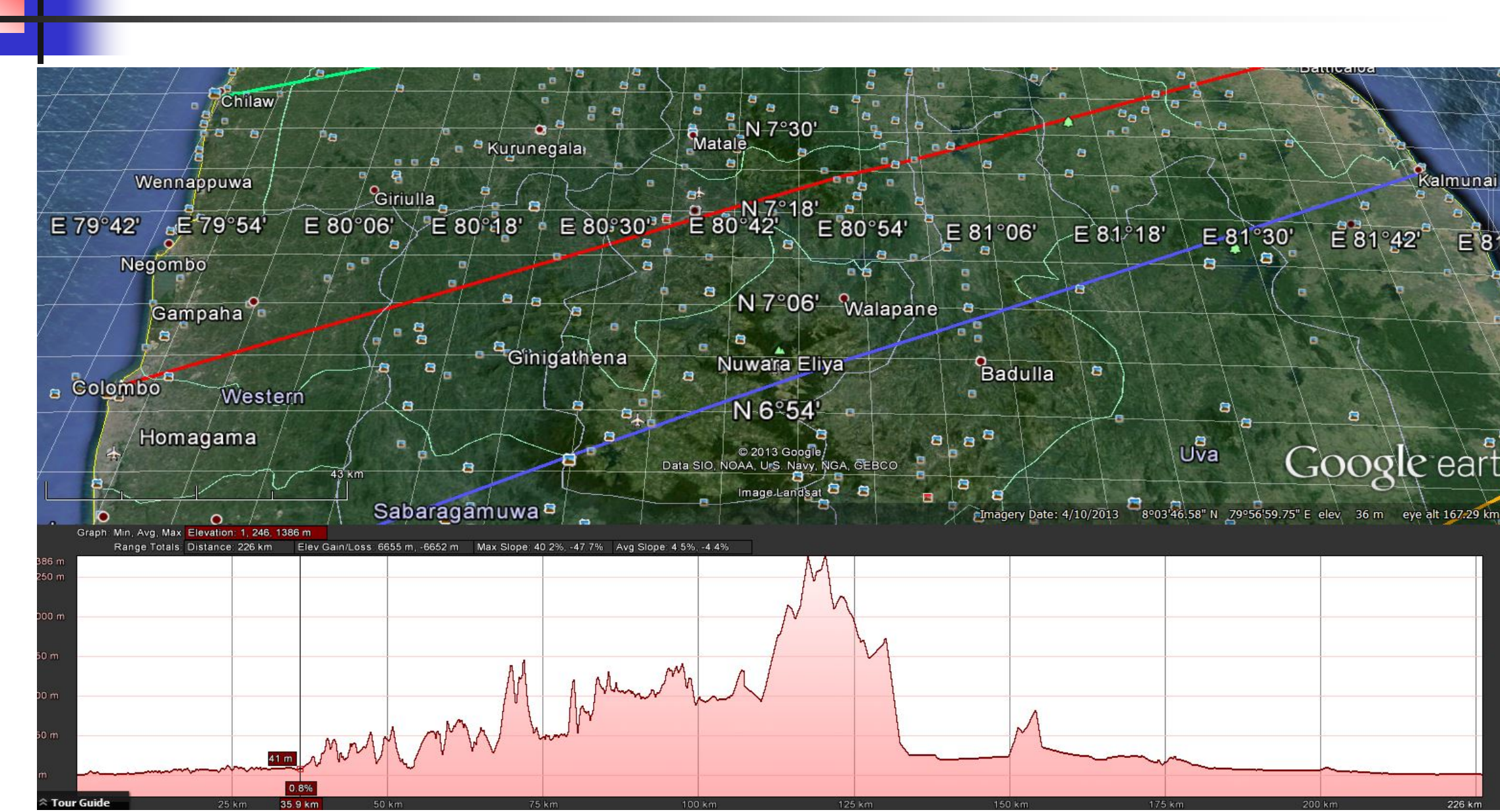




\section{Details of the Model}

- Google Earth ${ }^{\circledR}$ maps were used to acquire the cross section

- Element size $100 \mathrm{~m} \times 100 \mathrm{~m}$

- Total size $15 \mathrm{~km}$ in height, $214 \mathrm{~km}$ in width

- Shear wave velocity $=5000 \mathrm{~m} / \mathrm{s}$

- Density

$=2000 \mathrm{~kg} / \mathrm{m}^{3}$

- Bulk Modulus

$=0.3 \mathrm{Gpa}$

- Shear Modulus $\quad=0.3 \mathrm{GPa}$ 


\section{Finite Difference Model}

- Cities: Colombo, Kandy, Hunnas and Pasikuda

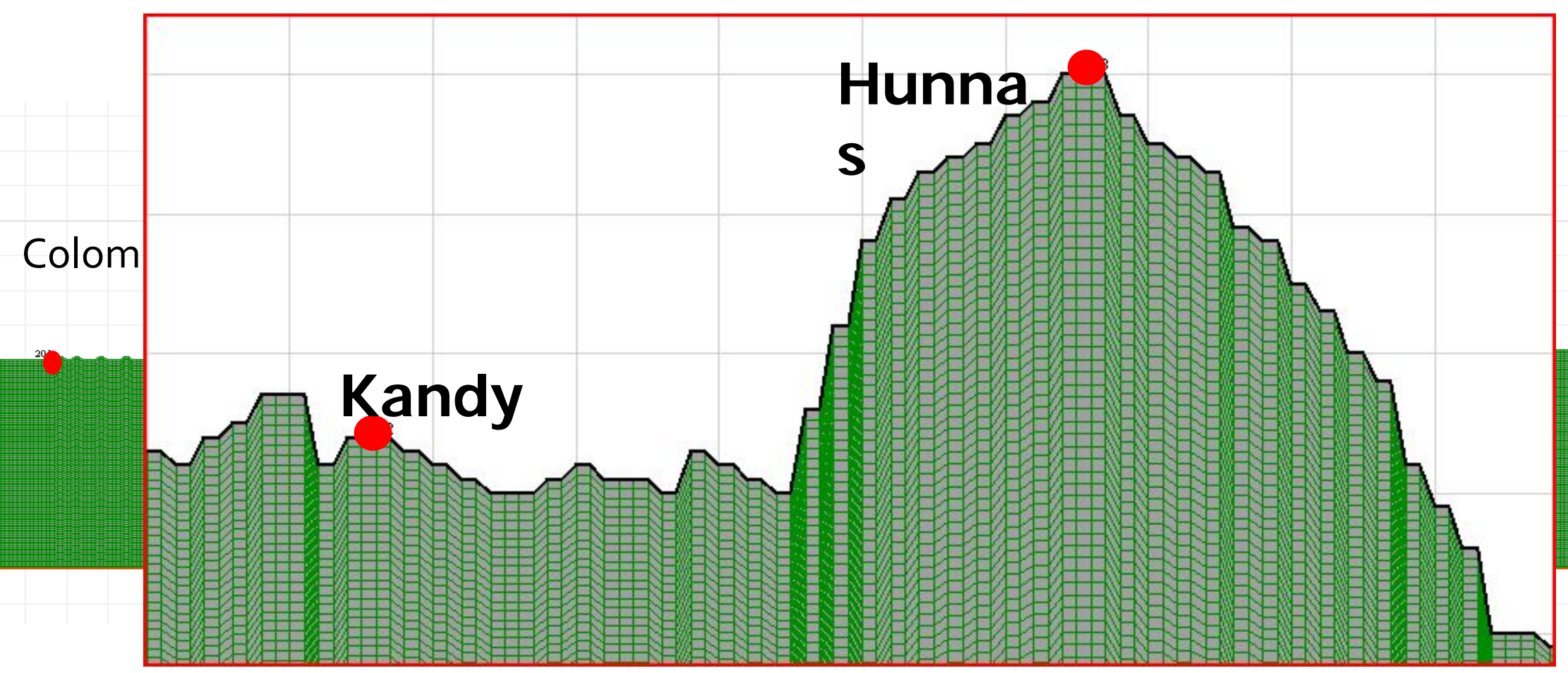




\section{Finite Difference Model}

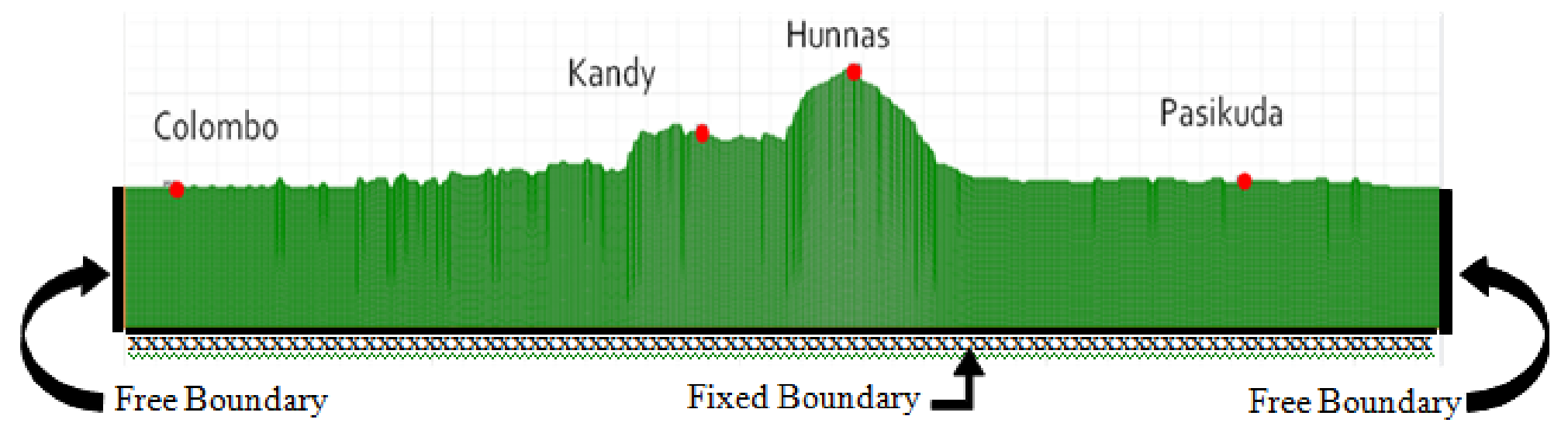

Developed FLAC 2D model

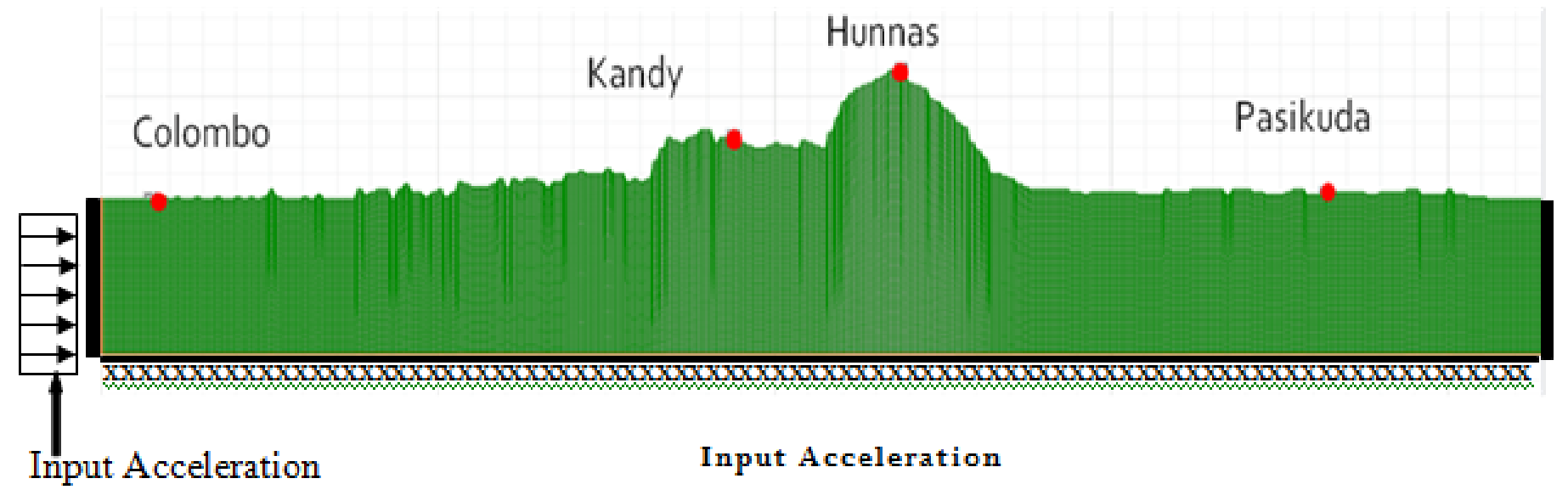




\section{Simulated Earthquake}

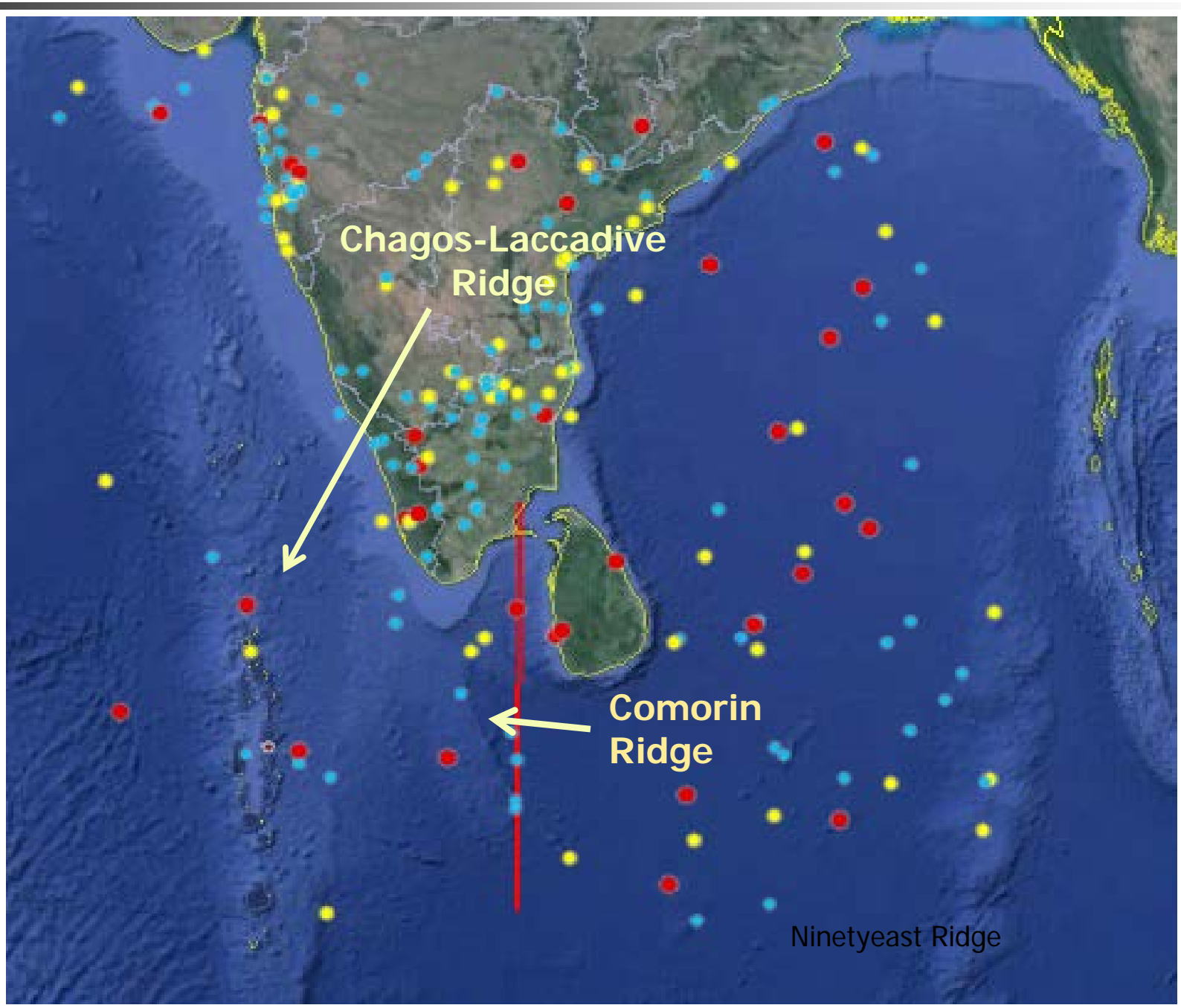




\section{Seismic I nput}

- Select 7 accelerograms from Intraplate earthquakes of magnitude around 7.4 recorded around $90 \mathrm{~km}$.

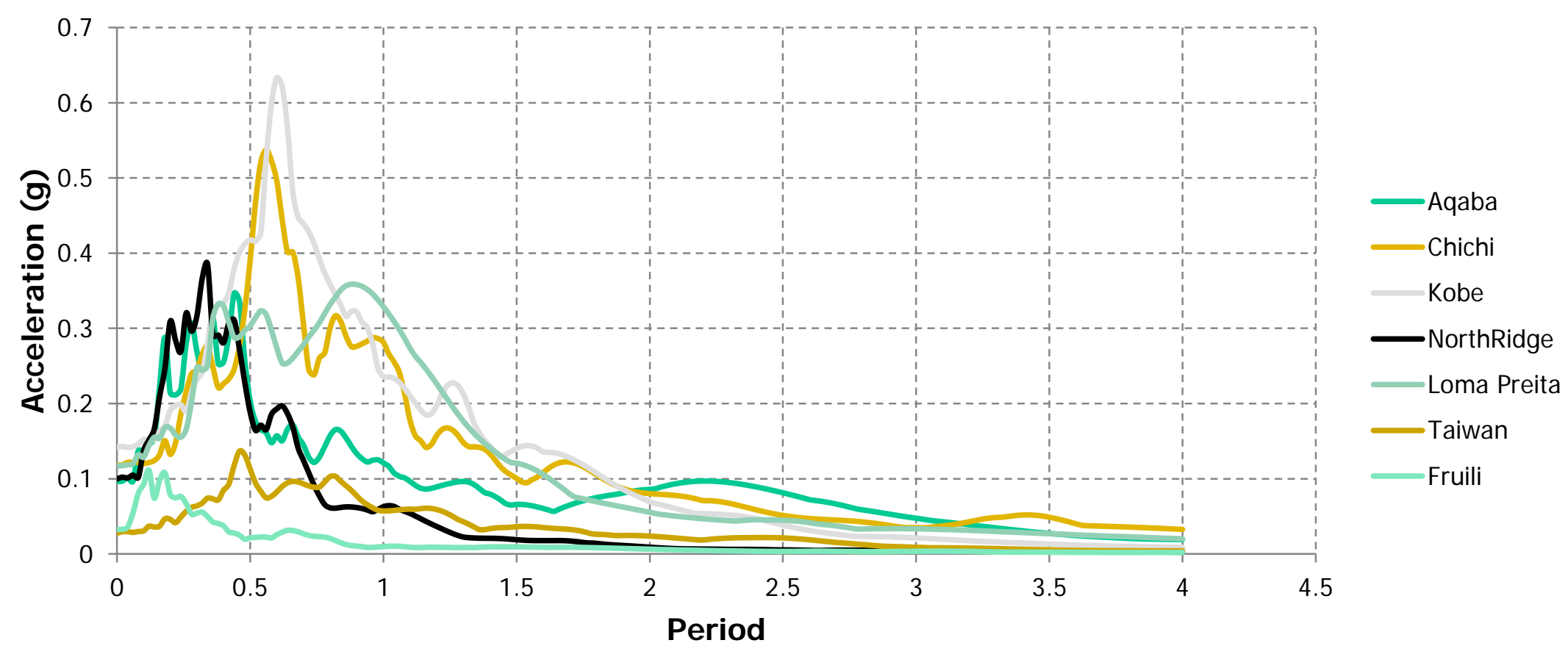




\section{Resultant Resonse Spectra}

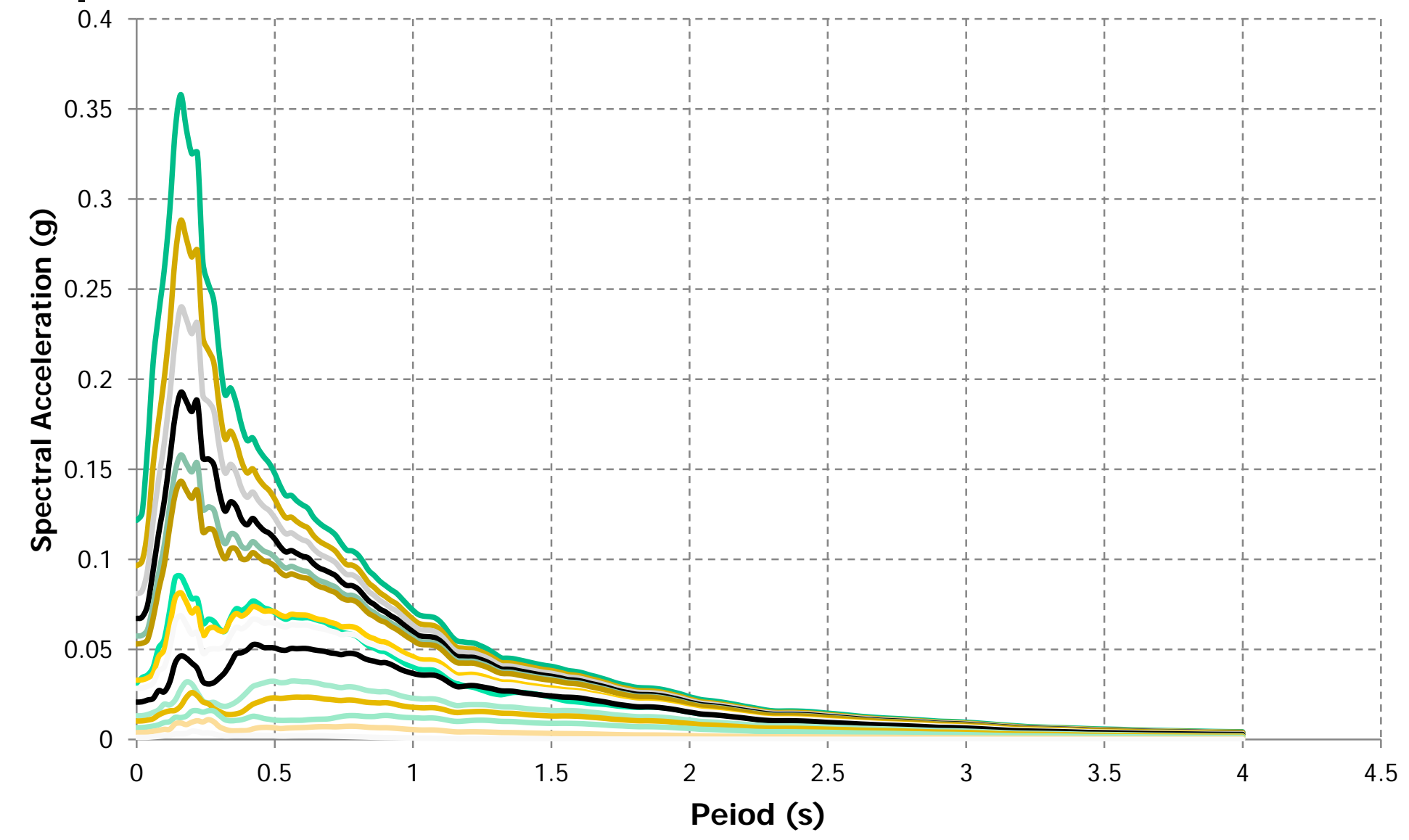

Colombo Fort

Colombo 13

Kotahena

Colombo 14

Sedawatta

_Peliyagoda

Himbutuwelgoda

Dalugama Kiribatgoda

Mahara

Weliweriya

_ Radawana

- Mawanella

Kandy Baticoloa 


\section{Proposed Zonation Map}

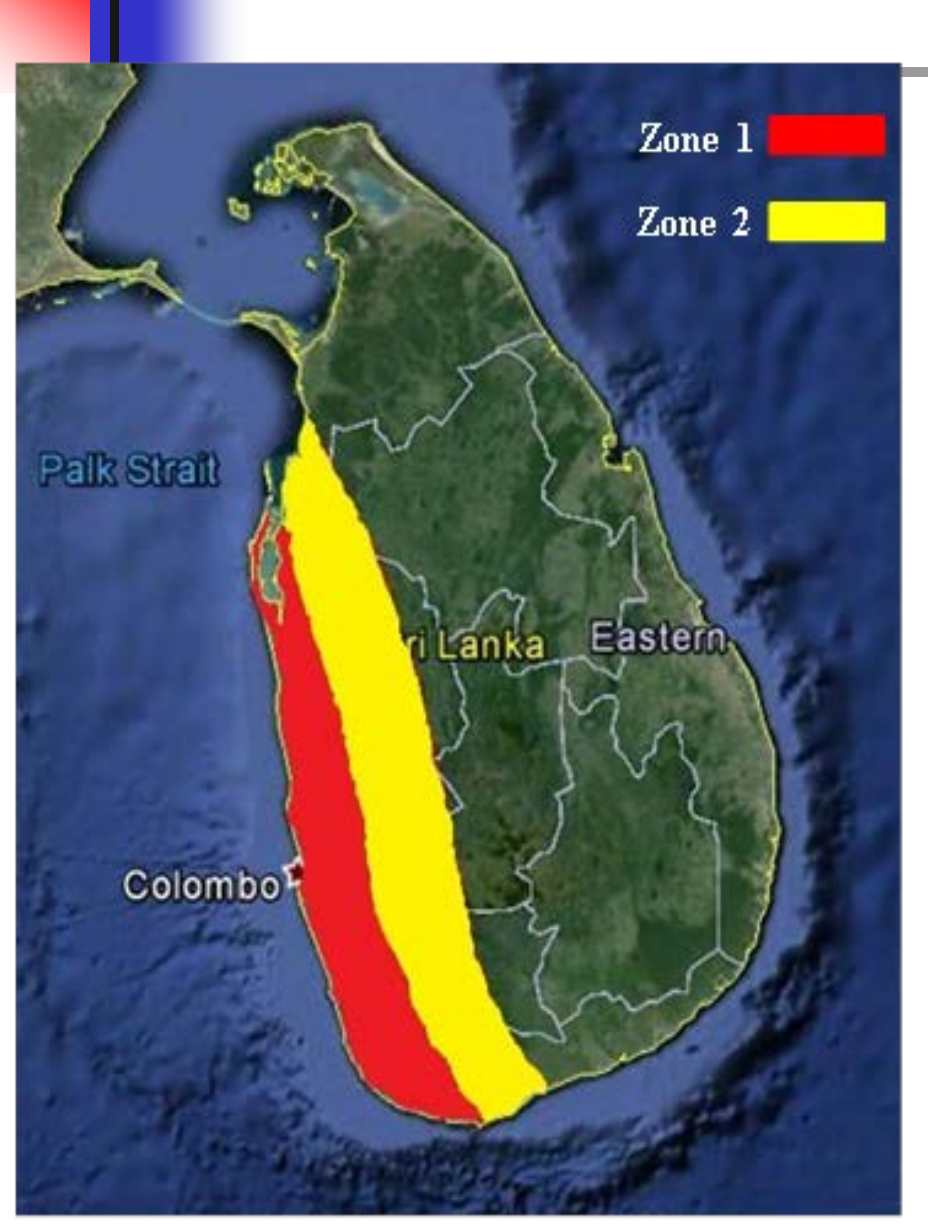

Zone Description

PGA Value(g)

Zone from the western coastal Belt

1

Zone $30 \mathrm{~km}-60 \mathrm{~km}$ from the western coastal Belt

2

Zone Rest of the country starting $60 \mathrm{~km}$ from the 3

\section{western coastal Belt}




\section{References}

- Seth Stein \& Michel Wysession, An Introduction to Seismology, Earthquakes and Earth Structures

- Seth Stein, Approaches to continental Intraplate earthquake issues

- Kaye M. Shedlock, I ntraplate eathquakes

- Steven L. Kramer, Geotechnical Earthquake Engineering 


\section{Acknowledgement}

- Department of Civil Engineering and Department of Geology, University of Peradeniya

- Disaster Management Center, Sri Lanka

- Geological Surveying and Mines Bureau

- Faculty of Engineering, South Asian Institute of Technology and Medicine 


\section{Thank You !!!}

